\title{
A deadly double dose for India's poor
}

\author{
Cooking with solid fuels is a major source of early death and ill health among lower-income Indians. The same \\ group also suffers disproportionately from air pollution generated by other, more general sources.
}

\section{Zoë Chafe and Sourangsu Chowdhury}

T he world's attention has been focused on one health issue over the past year: COVID-19. But substantially less attention is paid to a persistent and deadly problem: exposure to ambient air pollution. Breathing ambient air with unsafe levels of fine particulate matter $\left(\mathrm{PM}_{2.5}\right)$ causes approximately 4 million early deaths each year globally ${ }^{1}$, hundreds of thousands of which are among children. About 25\% of these deaths occur in India alone. Writing in Nature Sustainability, Rao et al. illuminate the double burden of air pollution experienced by the poorest households in India: smoke from burning wood, dung and other solid fuels in the home; and disproportionate exposure to ambient air pollution from general household consumption, caused particularly by affluent urban households that have higher consumption emissions per capita.

In the Global North, fossil fuel use for power generation, industry and land transportation contributes most to $\mathrm{PM}_{2.5}$ pollution $^{3}$. In India, however, smoke from solid fuel use for cooking and other household activities is the largest source of ambient air pollution. Recent studies ${ }^{4}$, including the one by Rao et al. ${ }^{2}$, have found that $20-50 \%$ of the pollutants in ambient air originate from residential solid fuel combustion (see Fig. 1). Household solid fuel use for cooking in India is associated with low socioeconomic status. In spite of initiatives by the Indian government to promote the use of liquefied petroleum gas, about $70 \%$ of the Indian population still depend on solid fuels for cooking, which produce more air pollution.

Vulnerable communities, whether defined by race or socioeconomic status, have disproportionately higher exposures to air pollutants ${ }^{5,6}$. Rao and colleagues quantify the disparity in exposure to ambient $\mathrm{PM}_{2.5}$ among income levels in India by combining emissions data with national level surveys and epidemiological models. The result is a poignant story in numbers of socioeconomic disparity in air-pollution-related impacts.

Multiple studies have described household solid fuel use and associated

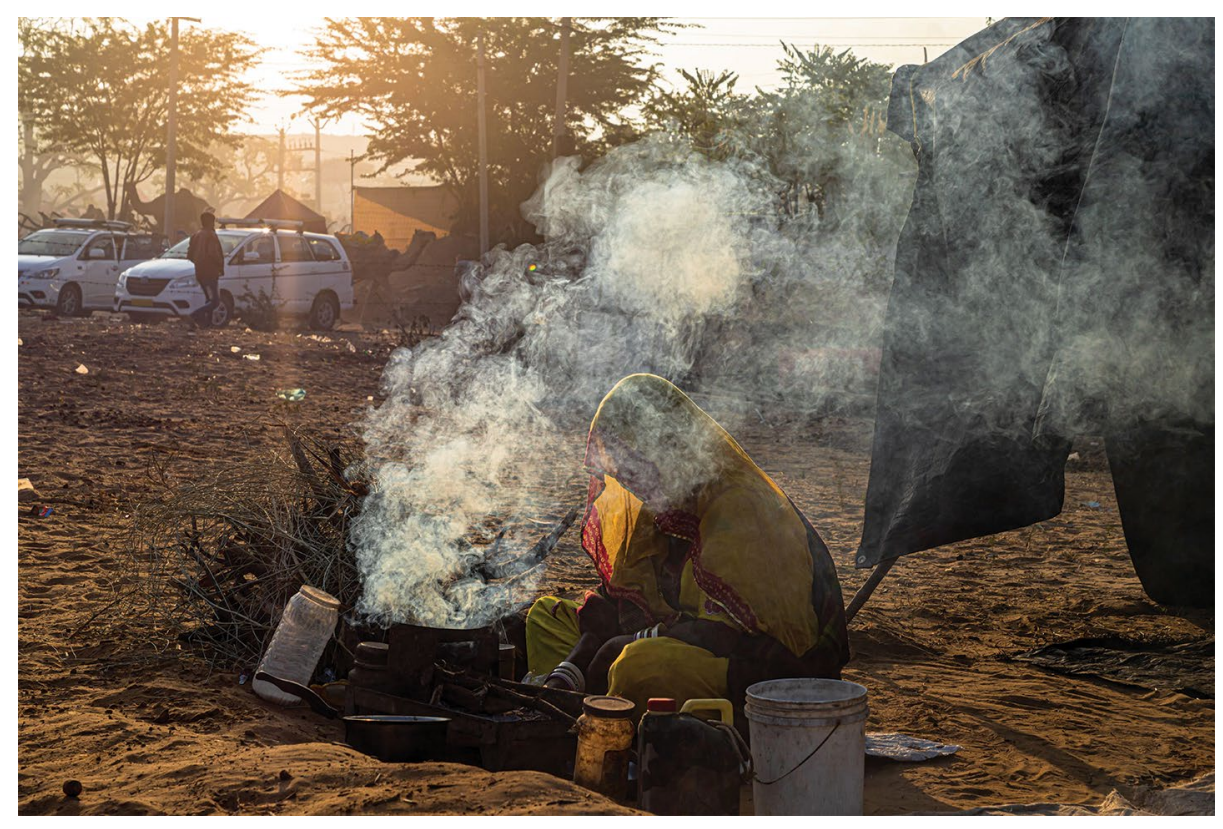

Fig. 1 | Like the cook in this picture, the least wealthy Indians suffer a tremendous air pollution burden. Rao et al. ${ }^{2}$ emphasize that lower-income households also suffer mortality risk from $\mathrm{PM}_{2.5}$ generated by higher-income households. But the authors find that providing access to cleaner cooking fuels is the most effective way to prevent premature deaths. Credit: Rohit Bhakar / Alamy Stock Photo

impacts in India ${ }^{7}$, and estimated the contribution of this use to ambient air pollution ${ }^{4}$. Here, the authors go a step further by examining all household activity and energy use (called 'consumption'). They compare direct (solid fuel use for cooking and heating, kerosene lighting) and indirect (food and food waste, clothing, transport, electricity) air pollutant emissions within the household consumption sector. They then compare household consumption emissions to 'other' consumption emissions (governmental and non-profit activity, exports), transboundary pollution and dust.

The authors find that lower-income households in India bear the brunt of air pollution from two important sources: first, they are more likely to cook with solid fuels and therefore are exposed to high levels of indoor air pollution; second, they are disproportionately impacted by exposure to air pollution from the household consumption of richer-income groups. This double burden on the poorest makes them at least nine times more likely to die from air pollution, compared with the richest, when each income group's relative contribution to air pollution is taken into account.

Indirect emissions from household consumption contribute more to ambient $\mathrm{PM}_{2.5}$ concentrations than direct emissions, and the contribution from the highest-income group to indirect emissions is many times greater than that from the poorest $10 \%$ of households. The health implications of this air-quality inequality are revealed through a scenario in which all solid fuel cooking emissions (magically) disappear: for the poorest groups, when considering health risks from ambient air pollution, the high-income group's indirect 
emissions are more harmful than solid fuel use directly in households.

There is a slightly counterintuitive way forward suggested by the paper: although end-of-pipe pollution controls could most dramatically reduce the inequality of exposure to household consumption emissions, across the income spectrum the most effective way to reduce the absolute number of deaths among the poorest groups would be to replace all household solid fuel combustion with affordable and accessible cleaner energy for cooking. This is because direct exposure to high concentrations of household cooking emissions is so much more harmful than exposure to cooking smoke dispersed in ambient air. Replacing all household solid fuel use with cleaner energy, such as liquefied petroleum gas or electricity, would avert a stunning eight times more premature deaths than end-of-pipe technology upgrades in other sectors.

Some open questions remain. Future analyses could more clearly separate household cooking and household space heating emissions. Separating these energy uses would allow for a more nuanced understanding of potential initiatives to reduce household air pollution. Also, emissions from household solid fuel burning, which include high levels of black carbon and precursors for secondary organic aerosols, may be more hazardous to human health than other components in $\mathrm{PM}_{2.5}{ }^{8}$. If so, the health effects of household air pollution may be even greater than what Rao et al. ${ }^{2}$ have estimated - meaning that the gap between rich and poor from air-pollution-related ill health could be even wider than reported.

Air pollution research in India is growing rapidly, and estimates of the devastating human toll from air pollution exposure abound. With their novel application of input-output modelling and assessment of air pollution contributions by income level, Rao et al. have opened a new door to quantitatively assess the environmental injustice experienced by millions of poor households in India: the double burden of household air pollution and higher exposure to ambient consumption-related pollution, especially pollution generated by the highest-income urban dwellers. They have also underscored the efficacy, necessity and equitable imperative of providing affordable, reliable access to clean cooking fuels for all.

\author{
Zoë Chafe ${ }^{1 凶}$ and Sourangsu Chowdhury ${ }^{2} \bowtie$ \\ ${ }^{1}$ C40 Cities, New York, NY, USA. ${ }^{2}$ Max Planck \\ Institute for Chemistry, Mainz, Germany.

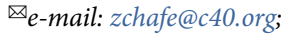 \\ sourangsuchowdhury@gmail.com
}

Published online: 26 July 2021

https://doi.org/10.1038/s41893-021-00752-0

References

1. Murray, C. J. L. et al. Lancet 396, 1223-1249 (2020).

2. Rao, N. D., Kiesewetter, G., Min, J., Pachauri, S. \& Wagner, F. Nat. Sustain. https://doi.org/10.1038/s41893-021-00744-0 (2021)

3. Lelieveld, J., Evans, J. S., Fnais, M., Giannadaki, D. \& Pozzer, A. Nature 525, 367-371 (2015).

4. Apte, J. S. \& Pant, P. Proc. Natl Acad. Sci. USA 116, 10614-10616 (2019)

5. Hajat, A., Hsia, C. \& O'Neill, M. S. Curr. Environ. Health Rep. 2, $440-450$ (2015).

6. Tessum, C. W. et al. Sci. Adv. 7, eabf4491 (2021).

7. Smith, K. R. et al. Annu. Rev. Public Health 35, 185-206 (2014).

8. Bates, J. et al. Env. Sci. Technol. 53, 4003-4019 (2019).

Competing interests

The authors declare no competing interests. 